\title{
STRAIN HETEROGENEITY AND THE PRODUCTION OF COARSE GRAINS IN MECHANICALLY ALLOYED IRON-BASE PM2000 ALLOY
}

\author{
C. Capdevila ${ }^{1}$, U. Miller ${ }^{2}$, H. Jelenak ${ }^{3}$ and H. K. D. H. Bhadeshia ${ }^{1}$ \\ ${ }^{1}$ Department of Materials Science and Metallurgy, \\ University of Cambridge, Pembroke street, Cambridge CB2 3QZ, United \\ Kingdom, www.msm.cam.ac.uk/phase-trans \\ ${ }^{2}$ Plansee GmbH / Lechbruck \\ Siebenbürgerstraße 23, D-86983 Lechbruck \\ Germany, www.plansee.com \\ ${ }^{3}$ MSR Metall-Spezialrohr \\ P.O. Box 3164, 58218 Schwerte \\ Germany, www.msr-special.com
}

\begin{abstract}
Mechanically alloyed iron-base ODS alloys have the potential for application in heat exchangers for biomass processing, with gas operating temperatures and pressures of around $1100{ }^{\circ} \mathrm{C}$ and $15-30$ bar. The yttria dispersion in such alloys improves the high-temperature creep and stress rupture life. The strength is enhanced by the development of a coarse-grained microstructure during recrystalllisation. Factors controlling the evolution of this desirable microstructure are explored in this work, focusing specifically on PM2000, which is a yttria dispersion strengthened, mechanically alloyed material. The results imply that anything which introduces a heterogeneity into the microstructure stimulates recrystallisation, so that a uniform strain is necessary to generate a coarsegrained microstructure.
\end{abstract}

\section{Introduction}

Coarse grained, Fe-base mechanical alloys which are oxide dispersion strengthened (MA-ODS) offer good combinations of creep and oxidation resistance in the context of tubes used to construct heat exchangers in equipment exploiting biomass for power generation.

PM2000 is an iron-base superalloy designed for power plant applications, strengthened with yttria particles $^{1}$. It is manufactured by mechanical alloying, a process in which elemental powders or compounds are heavily deformed whilst in intimate contact, to such large strains that the powder particles become solid solutions. The extremely fine and stable yttrium oxide particles, on the other hand, become dispersed uniformly throughout the microstructure. ${ }^{2}$ The alloyed powder is then canned and hot-extruded; the microstructure at this stage consists of incredibly fine $(\cong 0.5 \mu \mathrm{m})$ equiaxed grains of ferrite. ${ }^{3}$ Subsequent annealing at exceptionally high temperatures, of the order of 0.9 of the absolute melting-temperature, yields recrystallised grains which are columnar and aligned along the extrusion direction, giving excellent creep strength along the tube axis. ${ }^{4,5}$ The columnar growth is primarily a consequence of the alignment of oxide particles along the extrusion direction. However, in pressurised tubes, the maximum principal stress is in the hoop direction where the tubes are weakest in creep. ${ }^{6}$ To improve the hoop strength, tubes are deformed in torsion prior to heat treatment, in order to recrystallise the material into a helical grain structure which follows the twisted alignment of the oxide particles. ${ }^{7,8}$

Recrystallisation in commercial MA-ODS alloys occurs at very high temperatures, close to melting, in spite of their large stored energies. ${ }^{9,10,11}$ This is unlike conventional alloys which recrystallise at much lower homologous temperatures. ${ }^{12}$ It could be argued that recrystallisation is inhibited by the 
fine yttria dispersoids. However, this is inconsistent with experimental observations which indicate an insensitivity of the recrystallisation temperature to variations in the overall pinning force. ${ }^{13}$ Indeed, the limiting grain size in the presence of particles is far greater than the starting grain size.

There are indications that the activation energy for recrystallisation is very large, far greater than that for self-diffusion. ${ }^{14}$ Sha and Bhadeshia reported that recrystallisation happens at high temperatures and over a narrow temperature range during continuous heating. ${ }^{9}$ Cold-deformation of the consolidated produce has a dramatic effect on recrystallisation behaviour, as first recognised by Regle and Alamo ${ }^{15}$. The purpose of the present study was to analyse the effect of cold deformation on the nucleation and growth of recrystallised grains in a commercial MA-ODS iron alloy designated PM2000.

\section{Experimental procedure}

Sample of PM2000 (Fe-20Cr-5.5Al-0.5Y $\mathrm{Y}_{2} \mathrm{O}_{3}-0.5 \mathrm{Ti}$ wt\%) were supplied by PLANSEE GmbH. The essential feature of PM2000 is that it contains $5.5 \mathrm{wt} \%$ of $\mathrm{Al}$ and $0.5 \mathrm{wt} \%$ of $\mathrm{Y}_{2} \mathrm{O}_{3}$. The aluminium (along with chromium) enhances corrosion and oxidation resistance and it is claimed that PM2000 is better than other ODS metallic alloys in gaseous environments containing $\mathrm{SO}_{2} 0.24 \%, \mathrm{CO}_{2} 15 \%$, $\mathrm{O}_{2} 4 \%, \mathrm{~N}_{2}$ to balance. ${ }^{16,17}$ The creep performance has been found to be optimum with a $\mathrm{Y}_{2} \mathrm{O}_{3}$ content of $0.5 \mathrm{wt} \%$.

PM 2000 tubing is conventionally processed by unidirectional extrusion followed by heat treatment. This results in tubes with anisotropic, very coarse grained, axially aligned microstructures which exhibit excellent axial creep properties. However, in pressurised tubes, the maximum principal creep stress demands peak strength in the hoop direction so the tubing exhibits substantially weaker creep resistance in the hoop direction when compared with that along the tube axis. To overcome this problem, a novel processing route has been developed at MSR Metall-Spezialrohr GmbH. In this, the extruded tubes from Plansee are flow formed in a process of torsional extrusion, which leads to a reduction in wall thickness from $4.5 \mathrm{~mm}$ to $2.3 \mathrm{~mm}$. Flow forming is a process of chipless manufacture, in which the material of the tube is subjected to compressive stress between a mandrel (located inside the tube) and three work-rollers located symmetrically around its circumference. Due to the proprietary design of the rollers, the tube not only extends but also twists, the total deformation being a combination of torsion and extrusion.

It is well-established ${ }^{7,8}$ that the yttria particles in the iron-base MA alloys are aligned along the extrusion direction, probably because the powder particles used in the feedstock do not always contain identical quantities of yttria. Thus, on extrusion, they tend to align along the elongation direction of the particles, which in this case is also the extrusion direction. The purpose of this torsional deformation is to cause these axially aligned particles to turn into helical arrangements in the hope that the material then recrystallises into grains which twist along the extrusion axis and hence give better hoop strength.

Two types of samples have been produced, on in which the flow forming was conducted at room temperature (tube R) and the other in which the flow-forming was carried out at about $600{ }^{\circ} \mathrm{C}$ (tube W). Samples for metallographic examination were cut from the tubes as it is schematically shown in Fig. 1. Optical microscopy was used to observe the microstructures of heat treated specimens. The etchant used was $2 \mathrm{~g} \mathrm{CuCl}_{2}, 40 \mathrm{ml} \mathrm{HCl}$, and $40-80 \mathrm{ml}$ ethanol. 


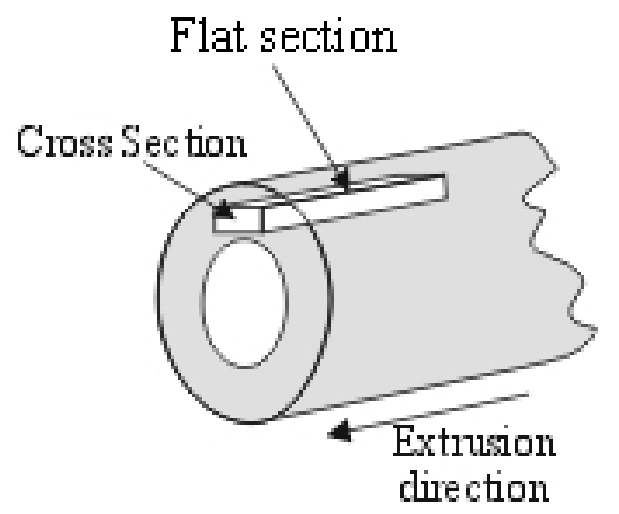

Figure 1. Diagram illustrating the sections on which metallographic examination was carried out.

\section{Results and discussion}

A variety of isothermal heat treatment experiments were conducted to study the recrystallisation behaviour of the flow-formed tubes. The minimum recrystallisation temperature $\left(T_{R}\right)$ is defined as the minimum temperature at which optical microscopy indicates some signs of recrystallisation following one hour of heat treatment. Values of these temperatures, for the inner and outer surfaces, were found to 975 and $750{ }^{\circ} \mathrm{C}$ respectively, for tube $\mathrm{R}$ in the flow formed condition..

Figure 2 shows the microstructure of tube R after recrystallisation heat treatment at $1380{ }^{\circ} \mathrm{C}$ for $1 \mathrm{~h}$. The outer microstructure consists of sheets of grains which have some tendency to helical alignment (Fig. 3), with the thin dimension along the radius of the tube. The inner microstructure comprises essentially coarse grains which from a creep point of view represent a better microstructure than that of the outer surface.

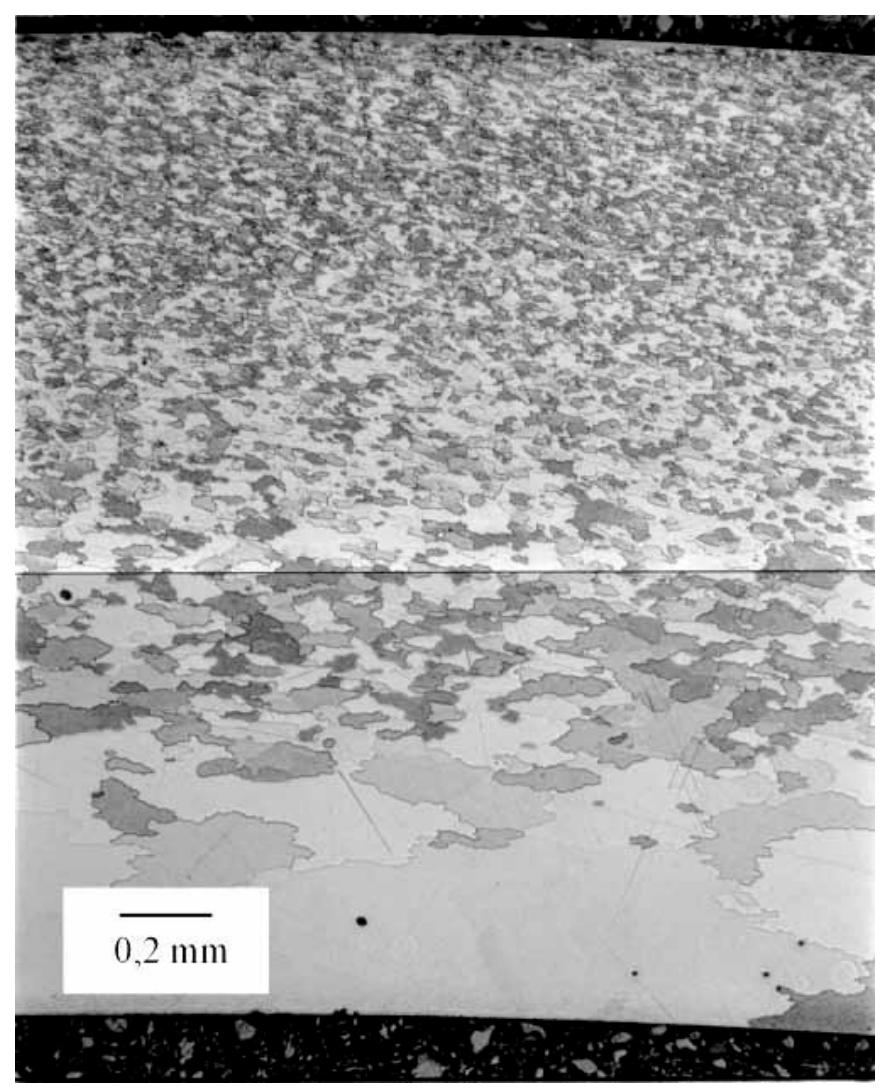

Figure 2. Cross section of tube $\mathrm{R}$ after subsequent recrystallisation at $1380{ }^{\circ} \mathrm{C}$ for $1 \mathrm{~h}$. 
Recrystallisation nucleates by the bowing of grain boundaries. With the sub-micrometer grain size of mechanically alloyed metals, the grain junctions themselves act as severe pinning lines for grain boundary bowing. ${ }^{18}$ The activation energy for the nucleation of recrystallisation thus becomes very large, giving the high recrystallisation temperatures characteristic of this material. However, this activation energy drops if a few grains happen to be slightly larger, i.e. if the grains are not uniform in size. ${ }^{19,20}$

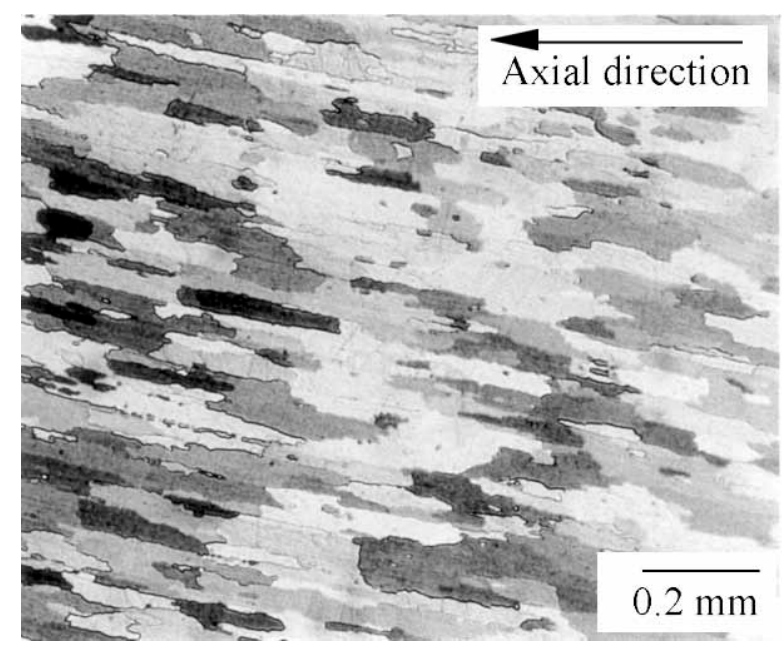

Figure 3. Flat section of tube $\mathrm{R}$ after subsequent recrystallisation at $1380{ }^{\circ} \mathrm{C}$ for $1 \mathrm{~h}$

It follows that a heterogeneous distribution of strain with its associated non-uniform distortions of the sub-micron cold-worked microstructure, makes the nucleation recrystallisation easier, leading to a reduction in $T_{R}$. This is precisely what is found. Assuming that recrystallisation takes place by means of a bowing mechanism, a non-uniform microstructure corresponding to inhomogeneous deformation assists nucleation by making available some grains which are sufficiently large to permit easy bowing. This would lead to a greater nucleation rate and hence a finer recrystallised grain size together with a smaller value of $T_{R}$, as is observed for the outer surface of tube R. By contrast, a uniform fine grain structure would find it more difficult to recrystallise and hence the few successful nuclei would develop into a coarse grained microstructure and $T_{R}$ would rise; this is exactly the case for the inner surface of tube R.

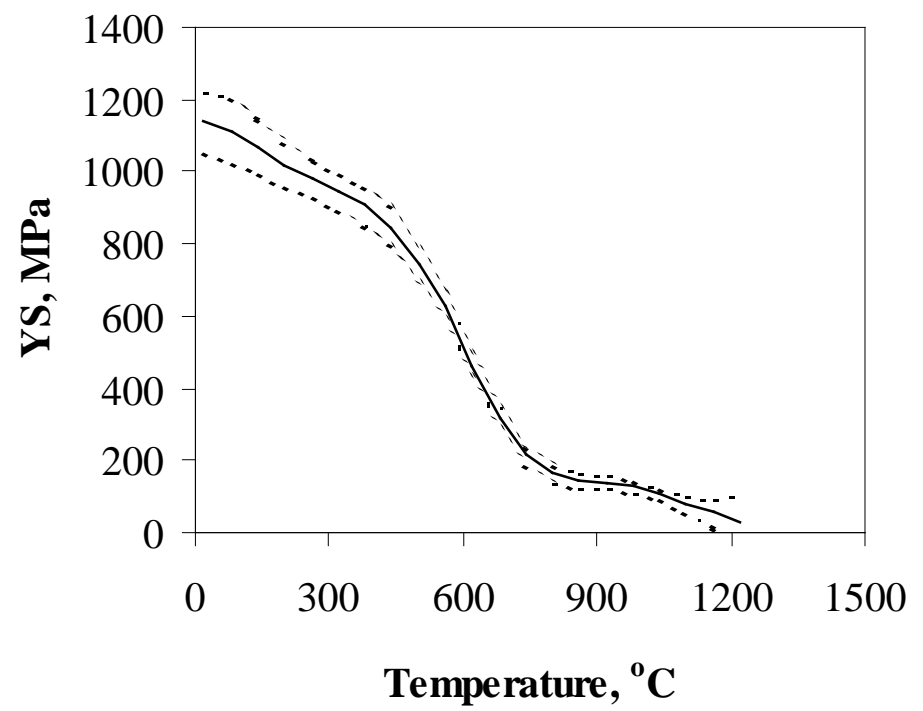

Figure 4. Effect of the temperature on yield strength (YS) of PM2000 calculated using the method of Badmos et al. ${ }^{21}$ 
Tube $\mathrm{R}$ has been flow-formed at room temperature, which should leave the tube surface more severely deformed than the tube interior. It is not surprising therefore that microstructure presented in Fig. 2 is fine and with low grain aspect ratios (GAR). The development of a coarse-grained structure requires a uniform distribution of deformation, i.e., a process which leads to a uniform cold-worked microstructure where the nucleation of recrystallisation is difficult.

How then, can the deformation be made more uniform? To resolve this, the deformation behaviour of PM2000 were estimated using the model created by Badmos et al., ${ }^{21}$ which has as inputs virtually all the parameters that are known to affect the strength. This includes the detailed chemical composition, any recrystallisation or ageing heat-treatment, the extent of cold work, the test temperature, and the strain rate. Figure 4 shows how the yield strength changes with temperature for the flow-formed material prior to its heat treatment. There is a significant drop in yield strength for temperatures in excess of $600{ }^{\circ} \mathrm{C}$. Therefore, flow forming at $600{ }^{\circ} \mathrm{C}$ might induce more homogeneous deformation when compared with room temperature where the yield strength is much higher. This was the basis for the manufacture of tube W. Figure 5 shows the microstructure obtained in the tube $\mathrm{W}$ after recrystallisation heat treatment at $1380^{\circ} \mathrm{C}$ for $1 \mathrm{~h}$. A notable difference in the grain structure as compare with that for tube $\mathrm{R}$ is observed. More homogeneous and coarse grain structure is obtained. Moreover, the tendency to helical alignment observed in tube $\mathrm{R}$ remains in tube $\mathrm{W}$.
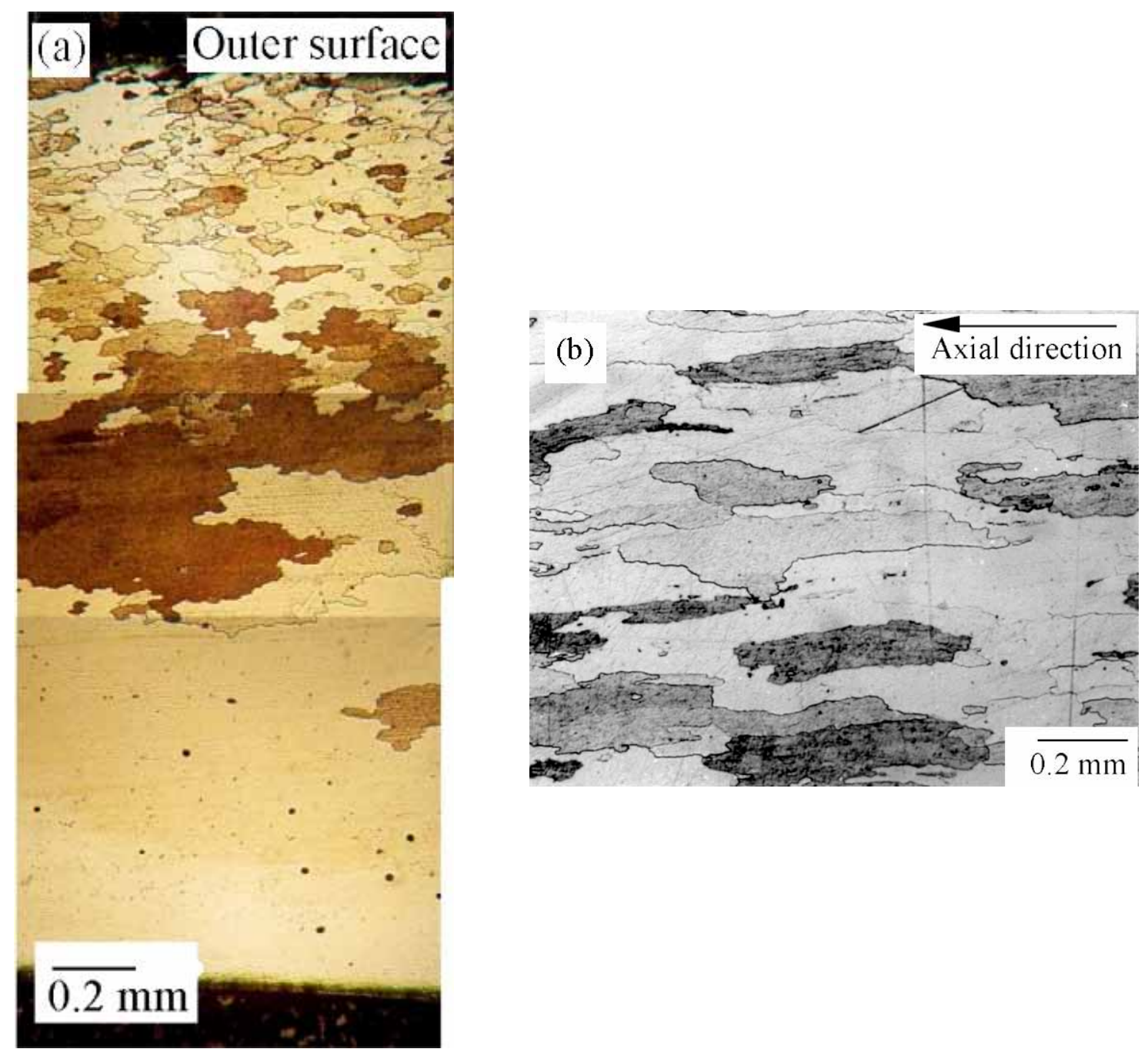

Figure 5. Microstructures obtained after recrystallisation heat treatment at $1380{ }^{\circ} \mathrm{C}$ for $1 \mathrm{~h}$ in tube W: (a) cross section and (b) flat section. 


\section{Conclusions}

The influence of deformation on the recrystallisation of mechanically alloyed PM2000 has been studied. Two different tubes manufactured at room temperature and $600{ }^{\circ} \mathrm{C}$ following a flow forming tube production route to introduce torsional flow to the material have been studied. Subsequent recrystallisation, will develop coarse, torsionally wound grain structures with substantially improved resistance to biaxial creep. The lower yield strength of PM2000 at $600{ }^{\circ} \mathrm{C}$ predicted using a published strength model, permitted the warm flow-forming which led to a more homogeneous deformation through the wall-thickness of the manufactured tube. Therefore, a coarser grain structure was obtained after recrystallisation.

\section{References}

1 D. Sporer and G. Korb, Procc. Of the 2nd International Conference on Structural Applications of Mechanically Alloying, Vancouver, British Columbia, Canada, (1993), p.109.

2 J. S. Benjamin, Metall. Trans., 1, (1970), p.2943.

3 D. Sporer and K. Lempenauer, Proceedings of 13th International Plansee Seminar, Eds. H. Bildstein and R. Eck, Metallwerk Plansee, Reutte, (1993), p.796.

${ }^{4}$ I. C. Elliot and G. A. J. Hack, in Proc. International Conf. Structural Applications of Mechanical Alloying, Ed: Froes and Barbadillo, ASM, Myrtle Beach, 15; 1990.

${ }^{5}$ T. Timmins and E. Artz, in Proc. International Conf. Structural Applications of Mechanical Alloying, Ed: Froes and Barbadillo, ASM, Myrtle Beach, 67; 1990.

${ }^{6}$ F. Starr, A. R. Whiteand B. Kazimierzak, in Proc. Conf. Materials for Advanced Power Engineering, Liege, 1994, Ed: Coutsouradis et al., Kluiver Academic Pub., 1393.

7 D.M. Jaeger and A.R. Jones, Proc. Conf. 'Materials for Advanced Power Engineering', Liege, Ed.: Coutsouradis et al., Kluwer Academic, (1993), 1994), p. 1515.

8 D.M. Jaeger and A.R. Jones, Proc. Conf. 'Materials for Advanced Power Engineering', Liege, Ed.: Coutsouradis et al., Kluwer Academic, (1993), 1994), p. 1507.

9 W. Sha and H. K. D. H. Bhadeshia, Metall. Mater. Trans. A, 25, (1994), p.705.

10 K. Murakami, K. Mino and H. K. D. H. Bhadeshia, Metall. Trans. A, 24, (1993), p.1049.

11 T. S. Chou and H. K. D. H. Bhadeshia, Mater. Sci. Technol., 9, (1993), p.890.

12 A. Cotrell, 'An Introduction to Metallurgy', Ed: E. Arnold, London, (1975), p. $402 .$.

13 C. P. Jongenburger and R. F. Singer, 'New Materials by Mechanical Alloying Techniques', Ed: E. Artz and L. Schultz, DGM- Infomationsgesellschaft, Obeerusel, (1989), p.157.

14 W. Sha and H. K. D. H. Bhadeshia, Mater. Science and Engineer., A223, (1997), p.91.

H. Regle and A. Alamo, Journal of Physique IV, C7, vol. 3, (1993), p.169.

16 . H. D. HEDRICH: in Proc. Conf. New materials by mechanical alloying techniques, 217-230; 1986; Ed: E.D. Artz and L. Schultz, Germany.

17. G. P. DeGAudenZI, F. UBERTI, F. BREGANI and G. P. TOLEDO: in Proc. High Temperature Materials for Power Engineering. Part II., 1563-1572; 1994, Ed: D. Coutsouradis et al., Brussels.

${ }^{18}$. H. K. D. H. BHADESHIA, Mater. Sci. Engineer., 1997, A223, 64-77.

${ }^{19}$ K.Murakami, PhD. Thesis, Cambridge University, 1993.

${ }^{20}$ K.Murakami, K. Mino, H. Harada and H.K.D.H. Bhadeshia, Metall. Trans. A, 25, (1994), 625653.

${ }^{21}$ A. Y. Badmos, H. K. D. H. Bhadeshia and D. J. C. Mackay, Mater. Sci. Technol., 14, 1998, 793809. 